УДК 551.577:51(480+470.22), 519.25

\title{
ОЦЕНКА СОСТАВА АТМОСФЕРНЫХ ОСАДКОВ ТЕРРИТОРИИ ФИНЛЯНДИИ И КАРЕЛИИ МЕТОДАМИ МНОГОМЕРНОГО АНАЛИЗА
}

\author{
Феоктистов Владимир Михайлович1, \\ feoktistov@petrsu.ru
}

\author{
Лери Марина Муксумовна², \\ leri@krc.karelia.ru \\ 1 Петрозаводский государственный университет, \\ Россия, 185910, г. Петрозаводск, пр. Ленина, 33. \\ 2 Федеральный исследовательский центр «Карельский научный центр РАН», \\ Россия, 185910, г. Петрозаводск, ул. Пушкинская, 11.
}

\begin{abstract}
Актуальность исследования обусловлена необходимостью достоверной оценки состава атмоссрерных осадков, выявления и распознания источников их загрязнения, а также поиска методик контроля антропогенного воздействия на окружающую среду. Анализируются данные, собранные на территории Финляндии и Республики Карелия в начале 2000-х г2. в рамках международного проекта «Экогеохимия Баренцева региона». Ценность именно этих исходньх данных обусловлена тем, что сбор проб атмосфрерных осадков, их подготовка и аналитическая обработка выполнялись строго по единой методике. Настоящая работа представляет собой продолжение предыдущих исследований, в которых был проанализирован состав атмосфрерных осадков российской части данного проекта.

Цель: изучить и сравнить химический состав атмосфрерных осадков нескольких пунктов наблюдений на территории Финляндии и Республики Карелия, оценить возможные источники их загрязнения, классифицировать пункты наблюдений и ассоциации химических элементов в атмосфрерных осадках.

Объекты: пять пунктов сбора атмоссрерных осадков на территории Финляндии и два на территории Республики Карелия. Методы: сбор месячных проб атмосферных осадков и подготовка проб по единой методике, масс-спектрометрия с индуктивно-связанной плазмой, математическая обработка результатов с помощью углубленньх методов многомерного статистического анализа, обобщение материала.

Результаты анализа фрормирования химического состава атмосфрерных осадков на территории Финляндии и части Республики Карелия в рамках проекта «Экогеохимия Баренцева региона» посредством иерархического факторного анализа показали определяющее значение нескольких различных фракторов первого порядка, обусловленных общими источниками происхождения. В качестве источников формирования состава атмосфрерных осадков показаны специсические и летучие продукты сжигания топлива, морские, земляные и почвенные аэрозоли. Факторы второго порядка выявили две независимые совокупности ингредиентов, присущие химическому составу атмосфрерных осадков исследованных пунктов наблюдений в зимнее и летнее время года. Классификация пунктов наблюдения посредством кластеризации показала степень их различия между собой. Кроме того, кластерный анализ элементного состава атмосфрерных осадков выявил сходную с результатами иерархического фракторного анализа картину распределения химических ингредиентов в атмосфферных осадках рассматриваемой территории.
\end{abstract}

\section{Ключевые слова:}

Атмосфрерные осадки, химический состав, кислотность, общие выпадения, МС-ИСП, иерархический фракторный анализ, кластерный анализ.

\section{Введение}

Химический состав атмосферных осадков (АО) остается одной из актуальных проблем экологических исследований. Первостепенное внимание уделяется поиску природных, городских и антропогенных источников их загрязнения [1-5], влиянию метеорологических условий на перенос загрязнителей [6-8], составу сухих и влажных выпадений [9], качеству дождевой воды для хозяйственных целей [10], а также её влиянию на здоровье человека и окружающую среду [11]. Так, недавно был проведен анализ состава АО Российского Заполярья [12]. Практически во всех вышеперечисленных работах для обобщения полученных аналитических результатов применяются математические методы одномерного и многомерного анализа данных. Использование этих методов обусловлено применением многоэлементных методов анализа (нейтронно-активационный анализ, рентгеновская флуоресценция, масс-спектрометрия с иони- зацией атомов в индуктивно связанной плазме (МСИСП) и др.), которые обеспечивают исследователя большим количеством информации. Осмыслить и интерпретировать такой объем полученных данных методами описательной статистики не представляется возможным.

Цель настоящей работы состояла в том, чтобы проанализировать состав химических ингредиентов, выпадающих с атмосферными осадками в пунктах наблюдений Финляндии и Республики Карелия по проекту «Экогеохимия Баренцева региона», а также установить и оценить возможные источники их загрязнения, классифицировать пункты наблюдений и выявить ассоциации химических элементов.

\section{Объекты и методика исследования}

Сбор образцов АО по проекту «Экогеохимия Баренцева региона» выполнен с июня 2000 по май 2001 г. на 25-ти станциях территории Российской Фе- 
дерации и на пяти на территории Финляндии. В данной работе рассматриваются результаты химического анализа проб АО, собранных на пяти пунктах территории Финляндии и двух пунктах на территории Республики Карелия. Все пункты сбора АО находятся вблизи небольших населенных пунктов. На территории Финляндии пункты наблюдений АО расположены по разрезу от Лапландии (Vuotsu) до побережья Балтийского моря (Sarkisalo) (рис. 1). Среднее расстояние между пунктами наблюдений - около 300 км. Максимальное число жителей проживает в Kuhmo (около 9 тысяч человек). Ранее [13-15] аналогичное исследование было проведено для станций севера европейской части России.

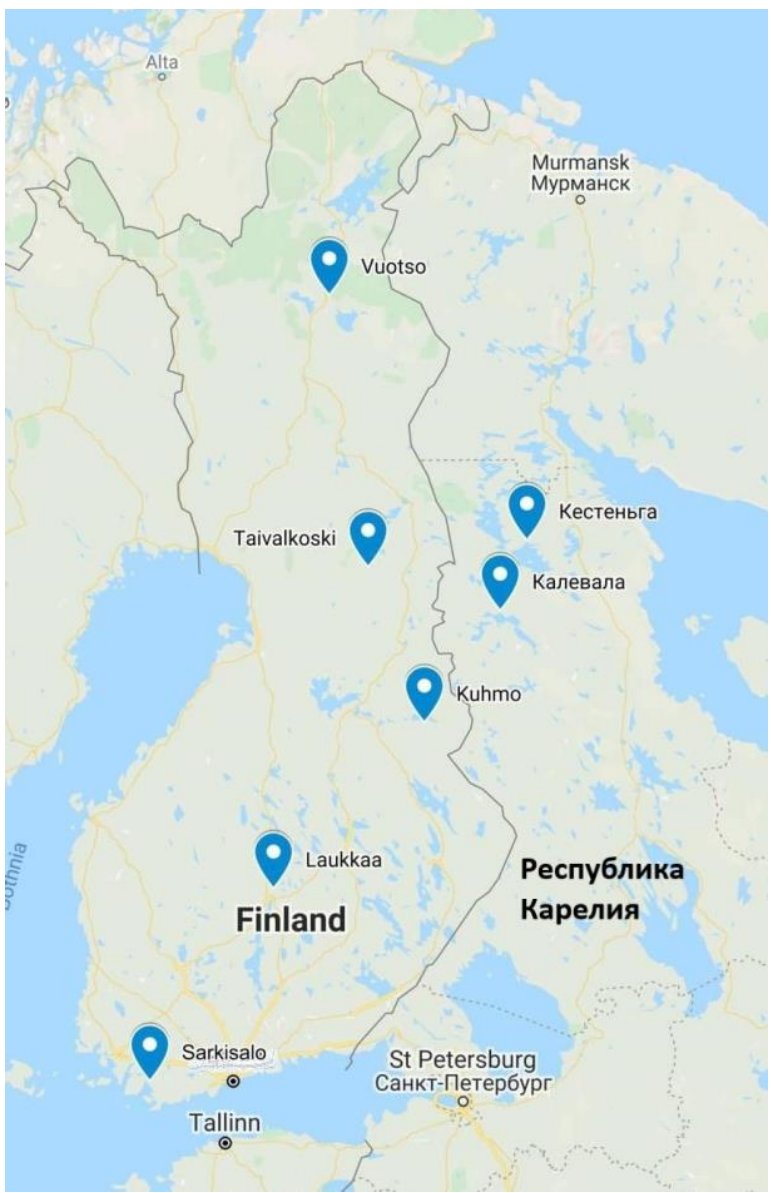

Рис. 1. Пункты отбора проб атмосферных осадков

Fig. 1. Collection stations of atmospheric precipitation samples

Пункты сбора АО на территории Республики Карелия расположены вблизи метеостанций «Кестеньга» и «Калевала» (рис. 1). По климатическим условиям они близки финским пунктам и также находятся на окраинах небольших населенных пунктов (до нескольких тысяч жителей). Здесь нет крупных промышленных предприятий. Приблизительно в 60 км на юго-запад от пгт. Калевала находится крупный источник антропогенных выбросов - Костомукшский ГОК с карьерами. В 100 и более километрах севернее п. Кестеньга располагается Кольский полуостров - крупнейший промышленный регион на северо-западе России.
На всей территории Баренцева региона отбор и обработка проб АО выполнялись по единой методике с использованием одинакового оборудования [16]. Подробно методика отбора проб АО и их аналитической обработки рассмотрена ранее в $[14,15]$. Пробы AО собирались в одноразовые полиэтиленовые мешки, располагавшиеся внутри сборников АО. Сборник представлял собой картонный цилиндр, снаружи покрытый алюминиевой фольгой. Среднюю пробу АО, выпавших за месяц, собирали автоматической пипеткой в два флакона. Пробы из первого флакона использовались для определения $\mathrm{pH}$, электропроводности и анионов $\left(\mathrm{SO}_{4}{ }^{-2}, \mathrm{NO}_{3}{ }^{-} \mathrm{Cl}^{-}\right.$и $\left.\mathrm{F}\right)$ методом ионной хроматографии. Из подкисленной пробы второго флакона с помощью метода МС-ИСП определяли микрокомпоненты: $\mathrm{Ag}, \mathrm{Al}, \mathrm{As}, \mathrm{B}, \mathrm{Ba}, \mathrm{Be}, \mathrm{Bi}, \mathrm{Br}, \mathrm{Ca}$, $\mathrm{Cd}, \mathrm{Co}, \mathrm{Cr}, \mathrm{Cs}, \mathrm{Cu}, \mathrm{Fe}, \mathrm{I}, \mathrm{K}, \mathrm{Li}, \mathrm{Mg}, \mathrm{Mn}, \mathrm{Mo}, \mathrm{Na}, \mathrm{Ni}, \mathrm{P}$, $\mathrm{Pb}, \mathrm{Rb}, \mathrm{S}, \mathrm{Sb}, \mathrm{Se}, \mathrm{Si}, \mathrm{Sn}, \mathrm{Sr}, \mathrm{Th}, \mathrm{Tl}, \mathrm{U}, \mathrm{V}, \mathrm{Zn}$. Подготовку проб к анализу и аналитические определения проб АО были выполнены в Espoo (Финляндия), в лаборатории Геологической службы.

Полученные результаты химического состава АО характеризуют суммарные (влажные и сухие) выпадения. Достоверность и правильность полученных результатов гарантируется системой аккредитации финской аналитической лаборатории.

В качестве массива исходных данных для статистической обработки используется совокупность результатов химических анализов проб АО всех станций. Из рассмотрения пришлось исключить часть микроэлементов (Ag, Be, Bi, Co, F, Cs, I, Li, Se, Sn, Th, $\mathrm{Tl}, \mathrm{U})$, содержание которых в пробах АO было ниже минимальных предельных значений обнаружения метода анализа.

\section{Методика многомерных анализов}

Факторный анализ (ФА), как один из методов снижения размерности данных, широко применяется российскими и зарубежными авторами для интерпретации результатов исследований. Цель использования этого анализа в данной работе состоит в сокращении количества исходных переменных путем формирования новых переменных (так называемых факторов) на основе их внутренних взаимосвязей. Факторы, полученные в результате этого, представляют собой интегральные группы ингредиентов, которые позволяют компетентно интерпретировать полученные результаты. Количество факторов существенно меныше числа исходных переменных, что значительно упрощает интерпретацию полученных результатов.

Под понятием «фактор» понимается совокупность химических ингредиентов, объединенных высокими факторными нагрузками. Высокая факторная нагрузка химического ингредиента показывает его значительный вклад в фактор. В факторном анализе, в отличие от метода главных компонент, который широко применяется на практике, можно рассчитать величину значения фактора каждой пробы АО. Эта возможность используется в работе для выявления динамики значений фактора в течение года для всех пунктов наблюдений. 
Иерархический факторный анализ (ИФА), использованный в настоящей работе, был опробован ранее в работах [13-15]. Вкратце можно отметить, что проведение этого анализа заключается в том, что из матрицы парных корреляций, стандартизованных значений концентраций химических показателей методом «максимального правдоподобия» с их косоугольным вращением, были получены факторы первого порядка Они могут быть коррелированы между собой и поэтому могут использоваться для получения независимых друг от друга факторов более высокого порядка [17]. Принадлежность фактора к тому или иному источнику формирования состава АО определялась как по собственным [14-16], так и по литературным данным [1-5].

Факторные нагрузки факторов первого и второго порядка, а также значения факторов первого порядка получены с помощью модуля «Факторный анализ» пакета «Статистика 10.0». Значения факторов второго порядка рассчитаны с помощью множественного регрессионного анализа [17] с использованием ПО «Wolfram Mathematica 9.0».

Кластерный анализ использован в данной работе как для сравнения пунктов наблюдений по совокупности всех результатов химического состава их АО, так и для выявления внутренних взаимосвязей отдельных химических ингредиентов между собой. Стандартизованные значения химических показателей исследуемых пунктов наблюдений обработаны методом Варда [18]. В качестве меры сходства (близости) между двумя объектами выбрано евклидово расстояние. Достоинством кластерного анализа является возможность наглядного изображения полученных отношений в виде дендрограммы.

\section{Результаты исследования и их обсуждение}

Ниже приводятся результаты рассмотрения и анализа химического состава АО на территории Финляндии и России, полученные в проекте «Экогеохимия Баренцева региона» (пять пунктов на территории Финляндии и два на территории Республики Карелия) Географическое положение пунктов сбора АО характеризуется удаленностью от крупных промышленных центров и расположением вблизи небольших населенных пунктов. Особенностью расположения пунктов наблюдения Финляндии является их меридиональное размещение с севера на юг страны, от Лапландии до побережья Ботнического залива. При этом расположение российских пунктов наблюдений АО (рис. 1) соответствует центральной части Финляндии (ближайший финский пункт - Kuhmo).

Химический состав АО отдельного пункта наблюдений обуславливается выбросами в атмосферу местных источников, метеорологическими условиями, а также загрязнителями, поступившими за счет трансграничного переноса с соседних территорий. В табл. 1 представлены среднегодовые и среднесе- зонные значения для зимнего (ноябрь-март) и летнего (апрель-октябрь) сезонов года концентраций химических ингредиентов для 82 образцов атмосферной влаги. Атмосферные осадки всех пунктов наблюдений имели слабокислую реакцию среды. В течение всего периода наблюдений значения $\mathrm{pH}$ для зимнего периода были достаточно однородны и составляли 4,36-4,78. Летом, под воздействием почвенных аэрозолей и эоловой пыли, кислотность АО понижалась до 5,04-6,26 ед. $\mathrm{pH}$.

Для большинства показателей химического состава АО на территории Финляндии можно отметить увеличение концентраций с севера на юг. Исключение составляют Мо и $\mathrm{Na}$, кроме прибрежного пункта наблюдений (Sarkisalo). Это объясняется, с одной стороны, тем, что естественные биологические процессы на севере Финляндии существенно заторможены из-за суровых северных условий. С другой стороны, плотность населения в центре и на юге значительно выше, и здесь сосредоточена основная промышленность. Зимой, как правило, наблюдается некоторое увеличение концентраций ряда показателей (As, $\left.\mathrm{S}, \mathrm{SO}_{4}^{-2}, \mathrm{~V}\right)$, что связано с попаданием в атмосферу продуктов сжигания различных видов топлива. Ранее отмечалось, что загрязнение АО юго-восточной Финляндии продуктами сжигания топлива значительно меньше, чем на территории России [19].

При общем рассмотрении можно отметить, что концентрации химических ингредиентов в составе $\mathrm{AO}$ на финской и российской территориях проекта были близки, при этом в АО п. Кестеньга наблюдались максимальные концентрации $\mathrm{Al}$ и $\mathrm{Fe}$. Необычно высокие концентрации ряда показателей в составе $\mathrm{AO}$ были обнаружены в летние месяцы года в Kuhmo (Mg, $\mathrm{K}, \mathrm{Mn}$ и $\mathrm{Rb}$ ). Исключение составляют AO Sarkisalo. Здесь явно прослеживается влияние морских аэрозолей, а также ингредиентов, характерных для антропогенной деятельности - сжигания топлива.

Надо отметить, что все рассматриваемые пункты наблюдений, как финской, так и российской территорий, располагаются вдали от крупных промышленных выбросов. Поэтому каких-либо существенных изменений антропогенной нагрузки на них нами не предполагалось.

\section{Иерархический факторный анализ}

Матрица концентраций рассматриваемых ингредиентов состояла из 28 показателей для 82 месячных проб АО. Посредством метода максимального правдоподобия с косоугольным вращением стандартизованных значений концентраций ингредиентов АО были получены шесть факторов первого порядка. На рис. 2 показана динамика месячных значений факторов первого порядка, полученных для рассматриваемых пунктов наблюдений. Для каждого фактора приведены переменные с наибольшими факторными нагрузками. 


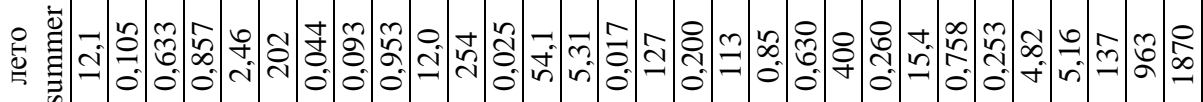
苞 $\frac{\pi}{3}$

焉

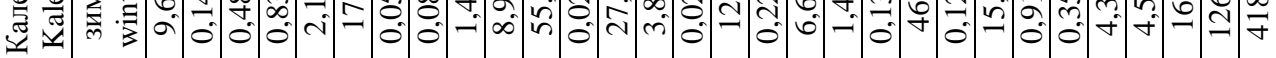

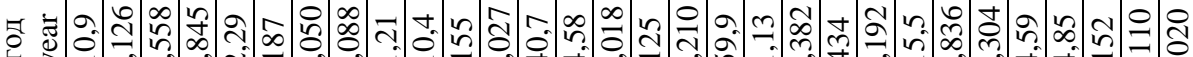

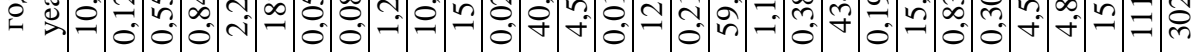

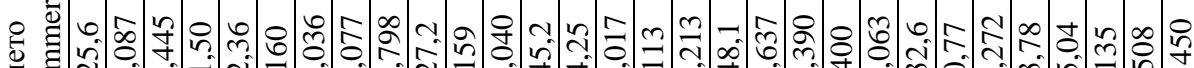
范

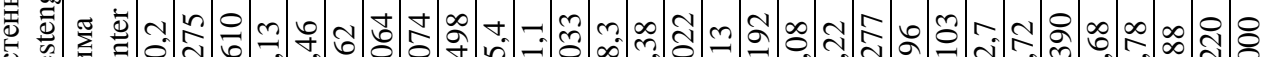

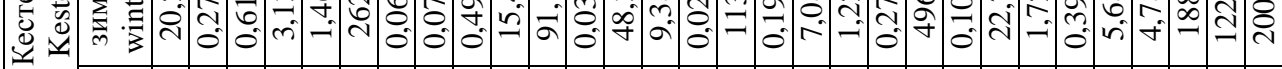

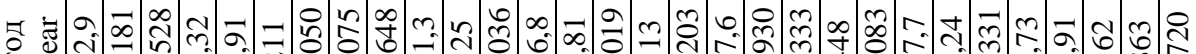

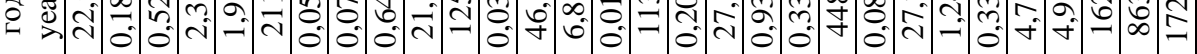

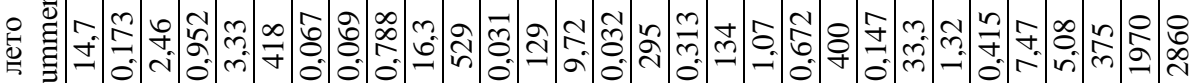

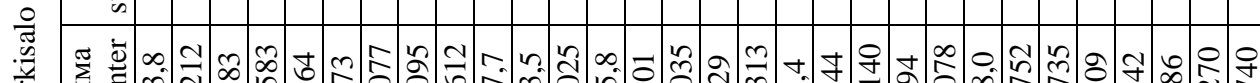

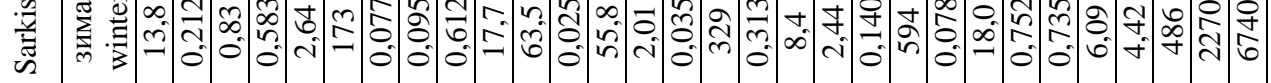

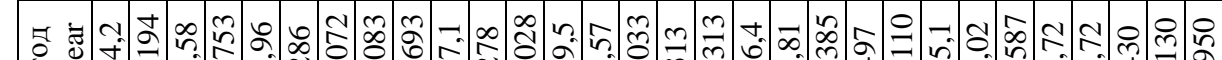

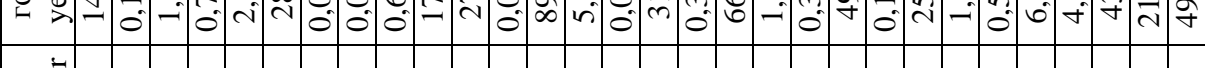

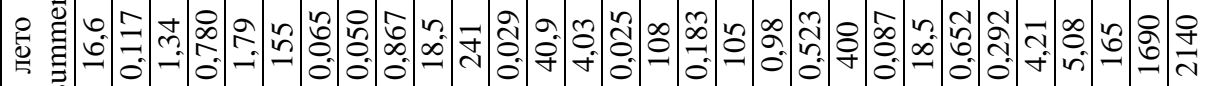

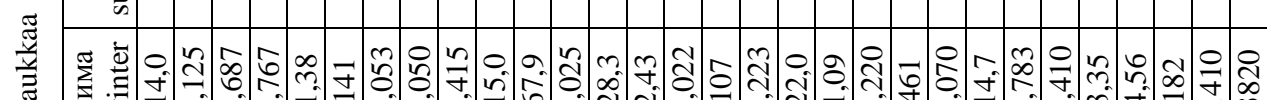

至

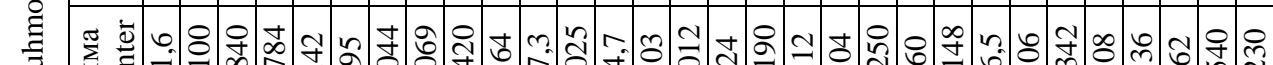

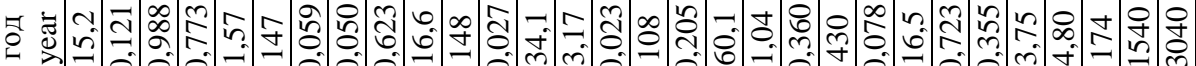

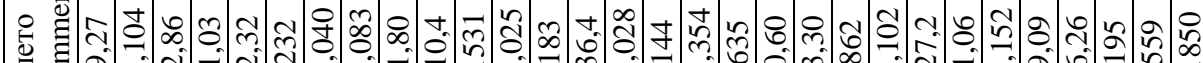

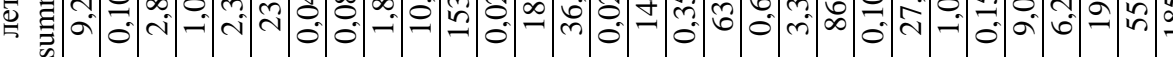

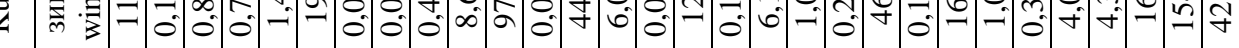

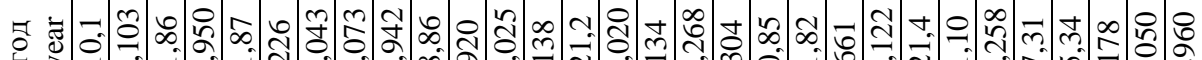
(1)

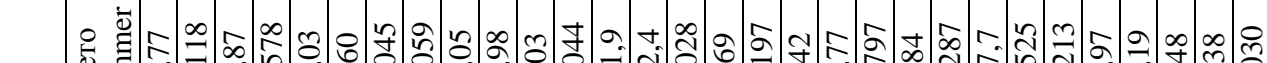

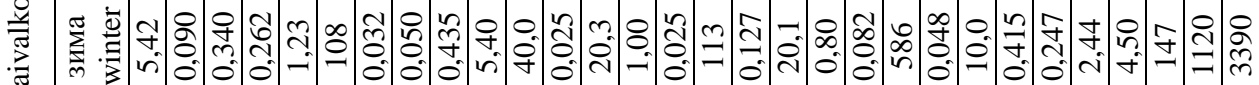

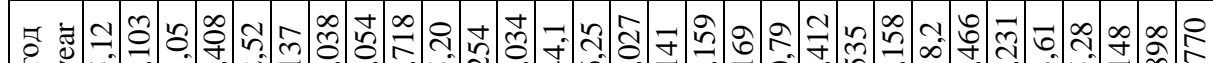

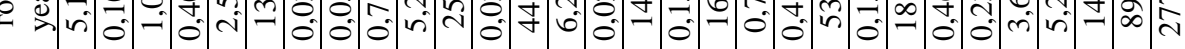

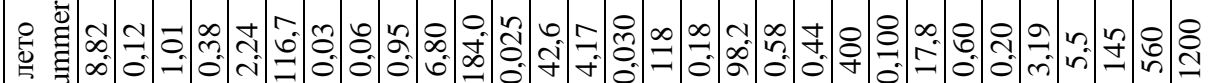

承

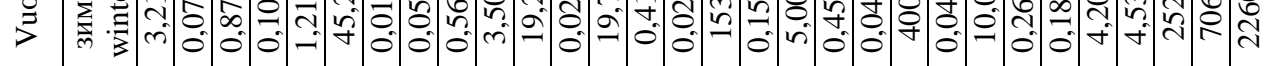

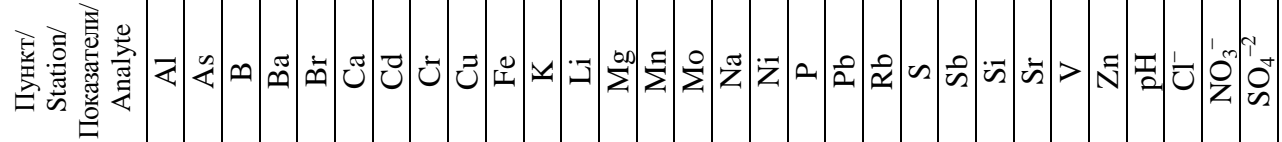



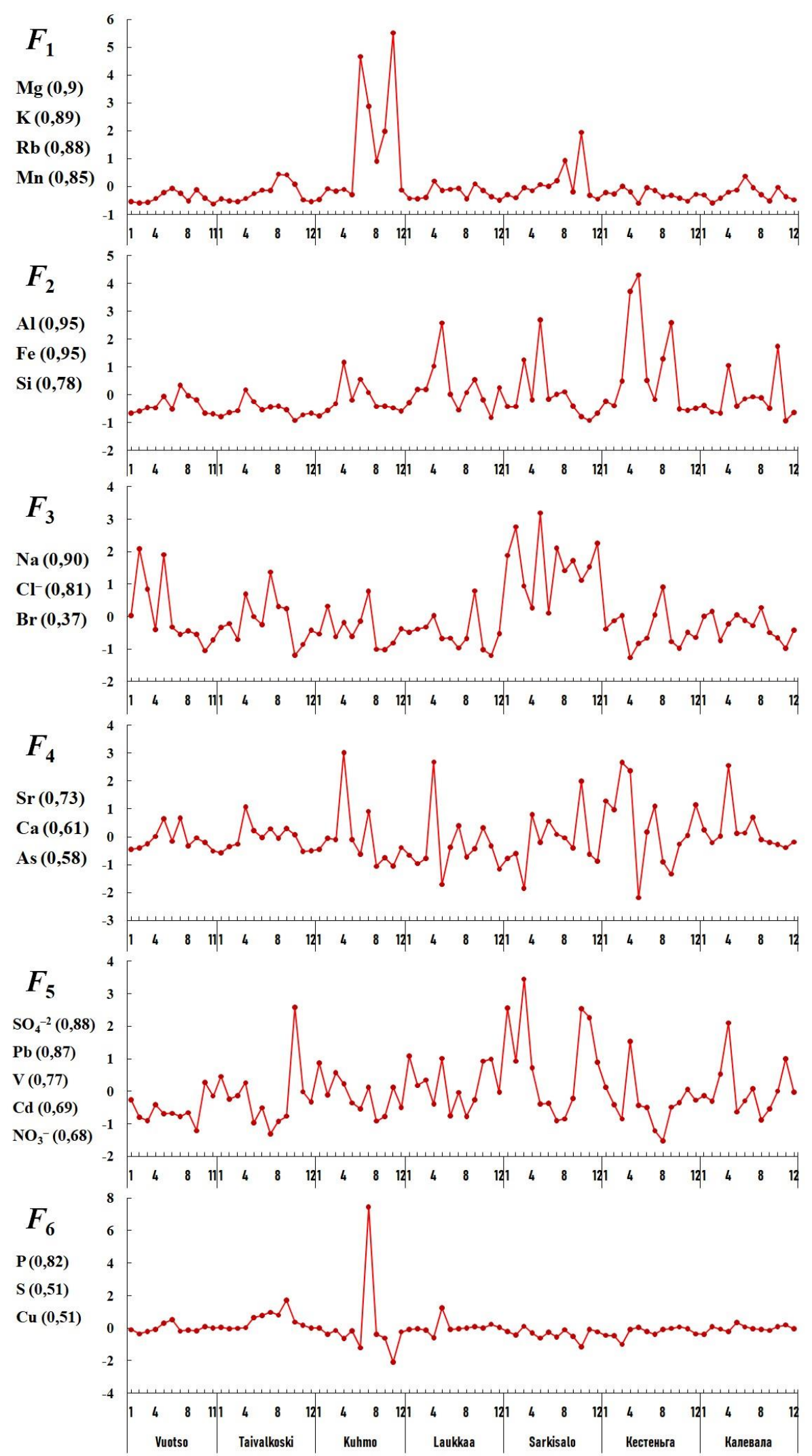

Pис. 2. Выраженность факторов первого порядка по составу и месяцам года по пунктам наблюдений: по оси абсиисс отмечены месячы года и названия пунктов наблюдений, по оси ординат - значения факторов $F_{1}-F_{6}$; для каждого фактора приведены элементы, вносящие максимальный вклад и величины их факторных нагрузок (в скобках)

Fig. 2. Severity of factors of the first order in composition and months of the year at observation stations: the abscissa marks the months of the year and the names of observation stations, the axis of ordinates shows the factors $F_{1}-F_{6}$; for each factor, elements are presented that make the maximum contribution and the values of their factor loads (in brackets) 
Вклад в полную дисперсию первого фактора $\left(F_{1}\right)$ первого порядка составляет $24,4 \%$. $F_{1}$ характеризуется высокими нагрузками элементов $\mathrm{Mg}, \mathrm{K}, \mathrm{Mn}$ и $\mathrm{Rb}$, a также средними нагрузками $\mathrm{Zn}$ и В. Максимальное значение этого фактора наблюдалось в июне и октябpe в AO Kuhmo. Для остальных пунктов наблюдений значения этого фактора минимальны (рис. 2). Подобное сочетание элементов (без марганца) встречалось авторами при изучении АО российских районов Баренцева региона [16], а также отмечалось в других работах (например, [19]). Элементный состав данного фактора предусматривает биологическое происхождение и связан в основном с деятельностью почвенных микроорганизмов. Высокая факторная нагрузка марганца, по-видимому, объясняется особенностями данного пункта наблюдений. В условиях кислого гумидного климата, характерного для северных территорий и Финляндии, марганец становится более «подвижным» [20] и может легко выносится из торфяных почв [21, 22]. Можно предположить, что данный пункт наблюдения был выбран неоправданно близко к месту расположения предприятия по добыче или переработке торфа. В результате получилось очень интенсивное местное воздействие почвенных аэрозолей на состав АО данного пункта, что в целом нетипично для территории Финляндии.

Для второго фактора $F_{2}(22,8$ \%) обнаружены высокие нагрузки микроэлементов $\mathrm{Al}, \mathrm{Fe}, \mathrm{Si}$. Наибольшие значения фактора наблюдались для АО п. Кестеньга (апрель, май, сентябрь), Sarkisalo, Laukka (май) и п. Калевала (апрель и октябрь). Состав этого фактора, а также его максимальные значения в весенний и осенний периоды года указывают на то, что его источником является аэрозоль земляной пыли. Так, для п. Кестеньга можно отметить малое количество дорог с асфальтовым покрытием, что и объясняет высокую концентрацию в этом пункте вышеназванных элементов.

Третий фактор $\left(F_{3}\right)(10,3 \%)$ имеет высокие нагрузки для ингредиентов $\mathrm{Na}$ и $\mathrm{Cl}^{-}$и среднюю для $\mathrm{Br}$ Эти показатели обусловлены влиянием морских аэрозолей $[3,16]$. Для AO Sarkisalo влияние этого фактора обнаруживалось практически весь год, так как этот пункт расположен на берегу моря. Стоит отметить поступление компонентов морского аэрозоля и для континентальных пунктов наблюдений - Vuotso (февраль и май) и Кестеньга (август). Это, повидимому, сопровождается также затоком холодного воздуха.

Четвертому фактору $\left(F_{4}\right)(5,7 \%)$ присущи максимальные значения факторных нагрузок ингредиентов $\mathrm{Sr}, \mathrm{Ca}, \mathrm{As}$ и Ba. Эти элементы наблюдаются в атмосферных выбросах при сжигании древесины, торфа и, частично, каменного угля (например, в п. Кестеньга). Кроме того, $\mathrm{Sr}$, As и Ва могут появляться в АO в результате влияния выбросов автомобильного транспорта [2].

Пятый фактор $\left(F_{5}\right)(4,8$ \%) характеризуется высокими нагрузками ряда специфических показателей $\left(\mathrm{SO}_{4}{ }^{-2}, \mathrm{~Pb}, \mathrm{~V}, \mathrm{Cd}\right.$, и $\left.\mathrm{NO}_{3}{ }^{-}\right)$. Эти показатели появляются в составе АО при сжигании различных видов топлива (в частности, мазута) [16]. Из рассматриваемых пунктов наблюдений наиболее характерная выраженность этого фактора отмечена для Sarkisalo. Здесь наблюдались высокие значения этого фактора в зимние месяцы года и резкое их уменьшение в летний период. Это показывает явное антропогенное влияние на состав АО. В других пунктах наблюдений часто отмечаются его высокие значения в начале весны (март, апрель) (рис. 2). Это явление отмечается не только для данного фактора, но также и для факторов $F_{2}$ и $F_{4}$ Установлено, что оно связано с более эффективным промыванием атмосферы жидкой каплей воды, чем кристаллической снежинкой [20].

В шестом факторе первого порядка $\left(F_{6}\right)(3,6 \%)$ выявлена высокая факторная нагрузка для фосфора Р и средние для $\mathrm{S}$ и $\mathrm{Cu}$. Максимальное и подавляющее значение этого фактора отмечено для Kuhmo (июль). Этот фактор, по-видимому, связан с первым фактором $\left(F_{1}\right)$, который также характерен для этого пункта наблюдений. Однако в настоящее время источник происхождения фактора $F_{6}$ определить трудно.

Отдельные факторы первого порядка показали значительные $(>0,5)$ коэффициенты корреляции между собой (табл. 2). Поэтому были вычислены два фактора второго порядка $\left(\Phi_{1}\right.$ и $\left.\Phi_{2}\right)$ (рис. 3). Они, в соответствии с методикой факторного анализа [17], ортогональны.

Таблица 2. Матрица коэффициентов корреляции между косоугольными факторами первого порядка

Table 2. Matrix of correlation coefficients between oblique factors of the first order

\begin{tabular}{|c|c|c|c|c|c|c|}
\hline $\begin{array}{c}\text { Фактор } \\
\text { Factor }\end{array}$ & $F_{1}$ & $F_{2}$ & $F_{3}$ & $F_{4}$ & $F_{5}$ & $F_{6}$ \\
\hline$F_{1}$ & 1 & & & & & \\
\hline$F_{2}$ & 0,32 & 1 & & & & \\
\hline$F_{3}$ & 0,43 & 0,37 & 1 & & & \\
\hline$F_{4}$ & 0,46 & 0,71 & 0,53 & 1 & & \\
\hline$F_{5}$ & 0,16 & 0,53 & 0,54 & 0,59 & 1 & \\
\hline$F_{6}$ & 0,70 & 0,39 & 0,51 & 0,39 & 0,21 & 1 \\
\hline
\end{tabular}

В составе первого фактора второго порядка $\left(\Phi_{1}\right)$ высокие факторные нагрузки имели микроэлементы Р, $\mathrm{Mg}, \mathrm{K}, \mathrm{Zn}, \mathrm{S}, \mathrm{Rb}, \mathrm{B}$. В его состав вошли ингредиенты первого и шестого факторов первого порядка. Максимальные значения $\Phi_{1}$ отмечены для летнего периода в Kuhmo (июль). В остальных пунктах наблюдения его значения более низкие, но также в летние месяцы года. Как было отмечено выше, фактор $F_{1}$ характеризуется вымыванием из атмосферы элементов микробиологического аэрозоля почвы. Сопоставление значений этого фактора на всех пунктах наблюдений свидетельствует о том, что его значение в Kuhmo следует отнести к антропогенному влиянию, нетипичному для природы изучаемого северного региона.

В состав $\Phi_{2}$ вошла большая группа показателей: $\mathrm{As}, \mathrm{Cd}, \mathrm{Pb}, \mathrm{V}, \mathrm{Sr}, \mathrm{Al}, \mathrm{Ca}, \mathrm{NO}_{3}^{-}$, $\mathrm{Fe}$ и $\mathrm{SO}_{4}{ }^{-2}$. Этот фактор сформирован ингредиентами второго, четвертого и пятого факторов первого порядка. В составе $\Phi_{2}$ представлены микроэлементы, привносимые аэрозолями земляной пыли, продуктами сжигания различ- 
ных видов топлив и, возможно, аэрозолями других антропогенных источников. Наиболее наглядно сочетание элементов этого фактора выражено в зимний период для пункта Sarkisalo. На остальных пунктах он представлен, как правило, в весенние месяцы. Как было отмечено ранее, это связано с переходом в это время года агрегатного состояния АО от твердого состояния (снег) в жидкое (вода).

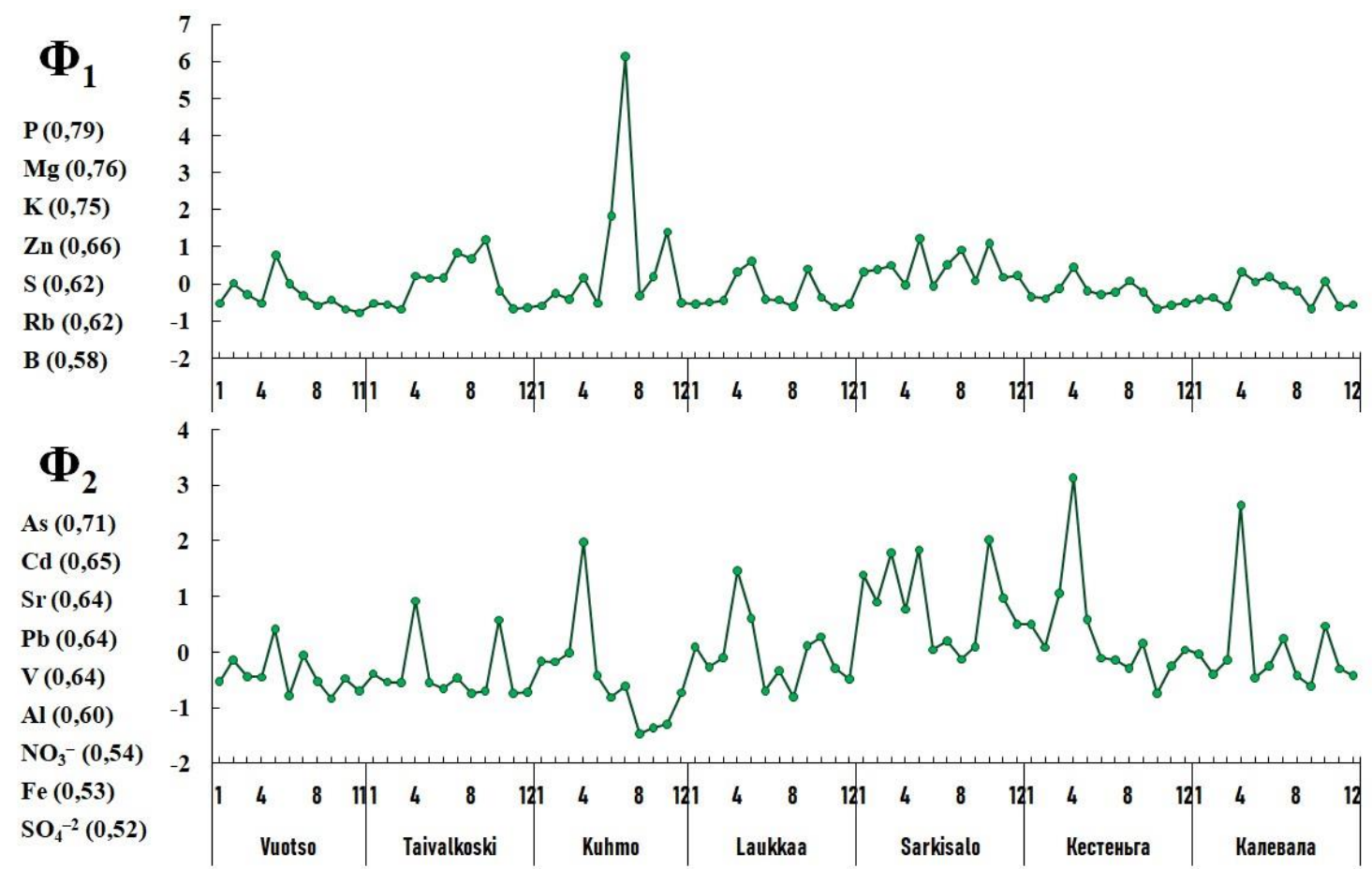

Рис. 3. Выраженность факторов второго порядка $\left(\Phi_{1}, \Phi_{2}\right)$ по составу и месяцам года по станциям наблюдений: см. обозначения к рис. 2

Fig. 3. Severity of factors of the second order $\left(\Phi_{1}, \Phi_{2}\right)$ in composition and months of the year at observation stations: see the notations in Fig. 2

\section{Кластерный анализ}

Для оценки степени сходства (различия) рассматриваемых пунктов наблюдений в работе проведен кластерный анализ по совокупности всех показателей. Методом Варда [18] была вычислена мера евклидова расстояния между парами отдельных пунктов наблюдений. Дендрограмма, представленная на рис. 4, показывает, что пункты наблюдений Sarkisalo, Kuhmo и Keстеньга имеют специфический состав АО и могут рассматриваться как отдельные кластеры. Это обусловлено их специфическим расположением на берегу моря (Sarkisalo) или местными условиями (Kuhmo и Кестеньга). Остальные четыре пункта образовали два кластера. По-видимому, условия формирования химического состава АО на севере Финляндии близки, и поэтому пункты Taivalkoski и Vuotso образовали один кластер. Пункты наблюдений Калевала и Laukka также характеризуются близким химическим составом АО.

Кластерный анализ химических показателей образцов АО исходного массива данных приведен на рис. 5. На дендрограмме выделяются два основных кластера - А и В. Кластер А состоит из нескольких под-кластеров, но все они объединены тем, что образованы элементами, входящими в состав почвенной аэрозоли. Эта аэрозоль образуется в процессе жизнедеятельности почвенных микроорганизмов и характерна для летнего сезона года.

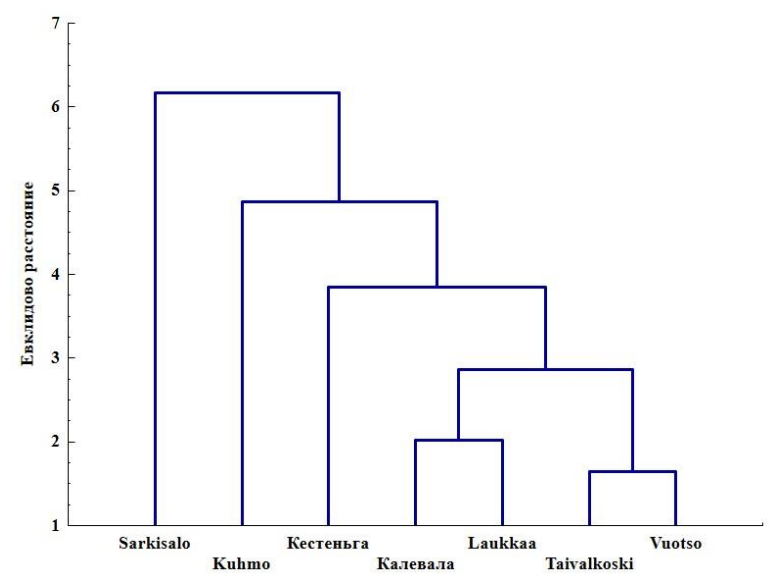

Рис. 4. Дендрограмма классификации станций наблюдений: по оси абсиисс приведены пункты отбора проб АО, по оси ординат - евклидово расстояние

Fig. 4. Observation stations classification dendrogram: the abscisse marks the names of observation stations, the axis of ordinates shows the Euclidean distances

Кластер В имеет более сложное строение. Он представлен под-кластерами нескольких уровней, которые в целом можно определить как кластеры, формирующиеся за счет аэрозолей различной природы. Ингредиенты, образованные из продуктов горения ископаемого топлива входят в кластер С. Элементы 
морского происхождения - в кластер D. В состав аэрозоли земляного (пылевого) генезиса и техногенного загрязнения вошли элементы, образующие кластер Е. Помимо основных элементов земной коры (Al,
$\mathrm{Fe}, \mathrm{Si})$ здесь можно отметить и ресуспендированные элементы от выбросов транспортных средств и, в частности, их тормозных систем ( $\mathrm{Sb}, \mathrm{Cu}, \mathrm{Cr}, \mathrm{Sr}, \mathrm{As}$, Ba) [2].

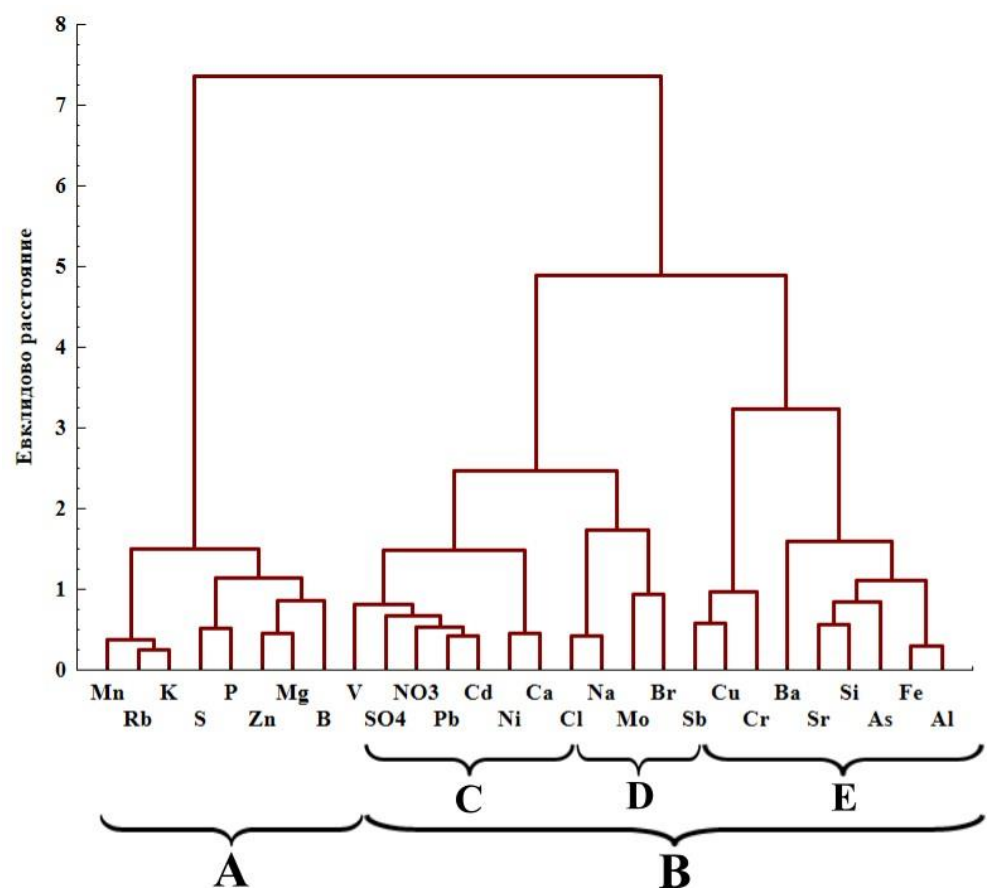

Рис. 5. Дендрограмма классификации рассматриваемых химических элементов, выпадающих с АО на станщиях наблюдений

Fig. 5. Dendrogram of classification of the considered chemical elements falling out with atmospheric precipitation at observation stations

\section{Заключение}

Качественный и количественный состав АО финской и российской территорий проекта «Экогеохимия Баренцева региона» в начале 2000-х гг. был довольно близок. Несмотря на кажущееся устаревание исходных данных, необходимо отметить, что местоположение рассмотренных в работе пунктов наблюдения и мало изменившееся вблизи их состояние окружающей среды позволяет считать эти результаты актуальными.

Использование иерархического факторного анализа позволило оценить химический состав АО территории Финляндии и Республики Карелия. Факторы первого порядка характеризуют основные источники формирования состава АО (специфические и летучие продукты сжигания топлива, морские, земляные и почвенные аэрозоли). Наибольшие концентрации химических показателей отмечены для AO Sarkisalo. Это связано не только с тем, что данный пункт наблюдения находится на берегу Балтийского моря, но и с выбросами продуктов сжигания ископаемого топлива. Факторы второго порядка $\left(\Phi_{1}, \Phi_{2}\right)$ обнаружили не только две ортогональные друг другу группы химических ингредиентов, но и показали их зависимость от состава АО сезонов года. Так, фактор второго порядка $\Phi_{1}$ в основном образован химическими показателями деятельности почвенных микроорганизмов и отображает состав АО летнего периода. Для Kuhmo, можно предположить, что высокое значение этого фактора объясняется тем, что этот пункт был расположен очень близко от источника почвенных аэрозолей.

В факторе второго порядка $\Phi_{2}$ преобладают ингредиенты аэрозолей земляной пыли и продуктов сжигания различных видов. Наибольшие значения для него отмечены в течение зимнего сезона.

С помощью кластерного анализа проведено классифицирование пунктов наблюдений за АО и показана степень их близости по химическому составу. Дендрограмма распределения химических ингредиентов в АО рассматриваемой территории обнаружила сходство с результатами иерархического факторного анализа.

Полученные результаты по программе проекта «Экогеохимия Баренцева региона» не позволяют оценить взаимное (трансграничное) влияние состава АО на состояние окружающей среды двух соседних стран. Наличие этого влияния не подлежит сомнению, так как для природы границ не существует. В этой связи отметим работу [23], в которой на примере нескольких тяжелых металлов (Pb, $\mathrm{Cu}, \mathrm{Ni})$ показано преимущественное влияние Финляндии и других стран Европы на территорию Республики Карелия из-за преобладающего над севером Евразии западного переноса воздушных масс.

Авторы выражают признательность руководителям проекта «Экогеохимия Баренцева Региона» за предоставленные результаты химических анализов проб атмосферных осадков. 


\section{СПИСОК ЛИТЕРАТУРЫ}

1. Mehr M.R., Keshavarzi B., Sorooshian A. Influence of natural and urban emissions on rainwater chemistry at a southwestern Iran coastal site // Science of The Total Environment. - 2019. V. 668. - № 10. - P. 1213-1221.

2. Montoya-Mayor R., Fernández-Espinosa A.J., Ternero-Rodríguez M. Assessment of the sequential principal component analysis chemometric tool to identify the soluble atmospheric pollutants in rainwater // Analytical and Bioanalytical Chemistry. - 2011. V. 399. - P. 2031-2041.

3. Siudek P., Frankowski M. Atmospheric deposition of trace elements at urban and forest sites in central Poland - Insight into seasonal variability and sources // Atmospheric Research. 2017. - V. 198. - P. 123-131.

4. Influence of marine, terrestrial and anthropogenic sources on ionic and metallic composition of rainwater at a suburban site (northwest coast of Spain) / J. Moreda-Piñeiro, E. AlonsoRodríguez, C. Moscoso-Pérez, G. Blanco-Heras, I. Turnes-Carou, P. López-Mahía, S. Muniategui-Lorenzo, D. Prada-Rodríguez // Atmospheric Environment. - 2014. - V. 88. - P. 30-38

5. Investigation of rainwater contamination sources in the southern part of Brazil / L. Hoinaski, D. Franco, R. Haas, R.F. Martins // Environmental Technology (United Kingdom). - 2014. - V. 35. № 7. - P. 868-881.

6. Siudek P., Frankowski M. The effect of sources and air mas transport on the variability of trace element deposition in central Poland: a cluster-based approach // Environ. Sci. Pollut. Res. 2017. - V. 24. - P. 23026-23038.

7. Northeastern Pacific submicrometer aerosol and rainwate composition: a multivariate analysis / R.J. Vong, H.-C. Hansson, H.B. Ross, D.S. Covert, R.J. Charlson // Journal of Geophysical Research. - 1988. - V. 93. - № D2. - P. 1625-1637.

8. Jain C.D., Madhavan B.L., Ratnam M.V. Source apportionment of rainwater chemical composition to investigate the transport of lower atmospheric pollutants to the UTLS region // Environmental Pollution. - 2019. - V. 248. - P. 166-174.

9. Assessment of atmospheric trace metal deposition in urban environments using direct and indirect measurement methodology and contributions from wet and dry depositions / M. Omrani, V. Ruban., G. Ruban, K. Lamprea // Atmospheric Environment. 2017. - V. 168. - № 11. - P. 101-111.

10. Monitoring of water quality from roof runoff: Interpretation using multivariate analysis / C. Vialle, C. Sablayrolles, M. Lovera, S. Jacob, M.-C. Huau, M. Montrejaud-Vignoles // Water Research. - 2011. - V. 45. - № 12. - P. 3765-3775.

11. Health risk associated with some trace and some heavy metals content of Harvested rainwater in Yatta Area, Palestine / I.A. AlKhatib, G.A. Arafeh, M. Al-Qutob, S. Jodeh, A.R. Hasan,
D. Jodeh, M. van der Valk // Water (Switzerland). - 2019. V. 11. - № 238. - P. 1-16.

12. Семенец Е.С., Свистов П.Ф., Талаш А.С. Химический состав атмосферных осадков Российского Заполярья // Известия Томского политехнического университета. Инжиниринг георесурсов. -2017 . - Т. 328. - № 3. - С. 27-36.

13. Феоктистов В.М., Харин В.Н., Спектор Е.Н. Применение иерархического факторного анализа для интерпретации выпадения химических элементов с атмосферными осадками на территории Карелии // Метеорология и гидрология. - 2007. № 12 . - С. $58-70$.

14. Феоктистов В.М., Харин В.Н., Спектор Е.Н. Структура выпадения химических элементов с атмосферными осадками на севере европейской части территории России, полученная с использованием методов многомерного анализа // Метеорология и гидрология. - 2008. - № 12. - С. 33-47.

15. Феоктистов В.М., Харин В.Н., Спектор Е.Н. Исследование химического состава атмосферных осадков по данным сельских станций Баренцева региона России методами многомерного анализа // Водные ресурсы. - 2014. - Т. 41. - № 4. C. $393-403$.

16. Volden T., Reimann C., Dagestad A. Precipitation sampling manual. Barents Ecogeochemisty. - NGU Report 99-128, 1999. $9 \mathrm{p}$

17. Иберла К. Факторный анализ / Пер. с нем. В.М. Ивановой. М.: Статистика, 1980. - 398 с.

18. Факторный, дискриминантный и кластерный анализ / Дж.-О. Ким, Ч.У. Мюллер, У.Р. Клекка, М.С. Олдендерфер, Р.К. Блэшфилд. - М.: Финансы и статистика, 1989. - 215 с.

19. Сравнительный анализ данных о составе атмосферных осадков и снежного покрова на территории Ленинградской области и юго-восточной Финляндии и уточнение параметров выпадения тяжелых металлов / Э.Я. Яхнин, О.В. Томилина, В.А. Чекушин, Р. Салминен // Экологическая химия. - 2003. T. 12. - № 1. - С. 1-12.

20. Мельчаков Ю.Л. Закономерности элементопереноса в системе «почва-атмосфера» (на примере Северного Урала) // Литосфеpa. - 2008. - № 2. - С. 133-138.

21. Юдович Я.Э., Кетрис М.П. Геохимия марганца в процессах гипергенеза: обзор // Биосфера. - 2013. - Т. 5. - № 1. - С. 21-36.

22. Завгородняя Р.Е. Микроэлементный состав некоторых торфяных почв Карелии разных сроков освоения // Ученые записки Петрозаводского государственного университета. - 2015. № 8 (153). - C. 111-114.

23. Виноградова А.А., Иванова Ю.А. Антропогенная нагрузка на экосистемы Костомукшского природного заповедника: Атмосферный канал. - М.: Физматлит, 2013. - 82 с.

Поступила 23.12.2020 2.

\section{Информация об авторах}

Феоктистов В.M., кандидат химических наук, доцент кафедры общей химии Института биологии, экологии и агротехнологий Петрозаводского государственного университета.

Лери М.М., кандидат технических наук, научный сотрудник Института прикладных математических исследований Карельского научного центра РАН Федерального исследовательского центра «Карельский научный центр РАН». 
UDC 551.577:51(480+470.22), 519.25

\title{
ASSESSMENT OF ATMOSPHERIC PRECIPITATION COMPOSITION IN THE TERRITORY OF FINLAND AND KARELIA REPUBLIC USING MULTIVARIATE ANALYSIS METHODS
}

\author{
Vladimir M. Feoktistov 1 , \\ feoktistov@petrsu.ru \\ Marina M. Leri2, \\ leri@krc.karelia.ru \\ 1 Petrozavodsk State University, \\ 33, Lenin avenue, Petrozavodsk, 185910, Russia \\ 2 Institute of Applied Mathematical Research of Karelian Research Centre of Russian Academy of Sciences, \\ 11, Pushkinskaya street, Petrozavodsk, 185910, Russia.
}

The relevance of the research is caused by the need for a reliable assessment of atmospheric precipitation composition, monitoring of anthropogenic impact on the environment, as well as identifying and recognizing sources of pollution. The article analyzes the data collected in Finland and the Republic of Karelia at the beginning of the 2000s as a part of the international project «Ecogeochemistry of the Barents region». These initial data are valuable as the collection of atmospheric precipitation samples, their preparation and analytical processing were carried out strictly according to a unified methodology. This work is a continuation of previous studies in which the composition of atmospheric precipitation of the Russian part of this project was analyzed.

The main aim of the research is to study and compare the chemical speciation of atmospheric precipitation of several observation stations in the territory of Finland and the Republic of Karelia, to evaluate possible sources of their pollution, to classify observation points and identify associations of chemical elements in atmospheric precipitation.

Objects: five collection stations of atmospheric precipitation on the territory of Finland and two stations in the Republic of Karelia.

Methods: monthly collecting of atmospheric precipitation samples and preparing these samples according to a unified methodology, inductively coupled plasma mass spectrometry, mathematical processing of the results using in-depth methods of multivariate statistical analysis, generalization of the material.

The results of the analysis of formation of atmospheric precipitation chemical composition in the territory of Finland and in the territory of the Republic of Karelia within the framework of the project «Ecogeochemistry of the Barents Region» by using hierarchical factor analysis showed the determining value of several different first-order factors having common sources of origin. Specific and volatile products of fuel consumption, marine, earth and soil aerosols are shown as sources of atmospheric precipitation composition. Second-order factors revealed two independent sets of ingredients inherent in the chemical composition of the atmospheric precipitation of the considered observation points in winter and summer. The classification of observation points by means of clustering analysis showed the degree of difference between these stations. In addition, a cluster analysis of the elemental composition of APs revealed a pattern similar to the results of hierarchical factor analysis of the distribution of chemical ingredients in the atmospheric precipitation of the territory.

Key words:

Precipitation, chemical composition, acidity, total precipitation, ICP MS, hierarchical factor analysis, cluster analysis.

The authors are grateful to the leaders of the project «Ecogeochemistry of the Barents region» for the provided results of ch emical analysis of precipitation samples.

\section{REFERENCES}

1. Mehr M.R., Keshavarzi B., Sorooshian A. Influence of natural and urban emissions on rainwater chemistry at a southwestern Iran coastal site. Science of the Total Environment, 2019, vol. 668, no. 10, pp. 1213-1221.

2. Montoya-Mayor R., Fernández-Espinosa A.J., Ternero-Rodríguez M. Assessment of the sequential principal component analysis chemometric tool to identify the soluble atmospheric pollutants in rainwater. Analytical and Bioanalytical Chemistry, 2011, vol. 399, pp. 2031-2041.

3. Siudek P., Frankowski M. Atmospheric deposition of trace elements at urban and forest sites in central Poland - Insight into seasonal variability and sources. Atmospheric Research, 2017, vol. 198, pp. 123-131.

4. Moreda-Piñeiro J., Alonso-Rodríguez E., Moscoso-Pérez C., Blanco-Heras G., Turnes-Carou I., López-Mahía P., MuniateguiLorenzo S., Prada-Rodríguez D. Influence of marine, terrestrial and anthropogenic sources on ionic and metallic composition of rainwater at a suburban site (northwest coast of Spain). Atmos pheric Environment, 2014, vol. 88, pp. 30-38

5. Hoinaski L., Franco D., Haas R., Martins R.F. Investigation of rainwater contamination sources in the southern part of Brazil. En- vironmental Technology (United Kingdom), 2014, vol. 35, no. 7, pp. 868-881.

6. Siudek P., Frankowski M. The effect of sources and air mass transport on the variability of trace element deposition in central Poland: a cluster-based approach. Environ. Sci. Pollut. Res., 2017, vol. 24, pp. 23026-23038.

7. Vong R.J., Hansson H.-C., Ross H.B., Covert D.S., Charlson R.J. Northeastern Pacific submicrometer aerosol and rainwater composition: a multivariate analysis. Journal of Geophysical Research, 1988, vol. 93, no. D2, pp. 1625-1637.

8. Jain C.D., Madhavan B.L., Ratnam M.V. Source apportionment of rainwater chemical composition to investigate the transport of lower atmospheric pollutants to the UTLS region. Environmental Pollution, 2019, vol. 248, pp. 166-174.

9. Omrani M., Ruban V., Ruban G., Lamprea K. Assessment of atmospheric trace metal deposition in urban environments using direct and indirect measurement methodology and contributions from wet and dry depositions. Atmospheric Environment, 2017, vol. 168 , no. 11, pp. 101-111.

10. Vialle C., Sablayrolles C., Lovera M., Jacob S., Huau M.-C., Montrejaud-Vignoles M. Monitoring of water quality from roof runoff: Interpretation using multivariate analysis. Water Research, 2011, vol. 45 , no. 12 , pp. $3765-3775$. 
11. Al-Khatib I.A., Arafeh G.A., Al-Qutob M., Jodeh S., Hasan A.R., Jodeh D., Van der Valk M. Health risk associated with some trace and some heavy metals content of Harvested rainwater in Yatta Area, Palestine. Water (Switzerland), 2019, vol. 11, no. 238, pp. 1-16.

12. Semenets E.S., Svistov P.F., Talash A.S. Chemical composition of atmospheric precipitation in Russian Subarctic. Bulletin of the Tomsk Polytechnic University. Geo Assets Engineering, 2017, vol. 328, no. 3, pp. 27-36. In Rus.

13. Feoktistov V.M., Kharin V.N., Spector E.N. Application of hierarchical factor analysis for interpretation of falling out of chemical elements with precipitation in the territory of Karelia. Meteorology and hydrology, 2007, no. 12, pp. 58-70. In Rus.

14. Feoktistov V.M., Kharin V.N., Spector E.N. The structure of falling out of chemical elements with precipitation in the north of the European part of Russia, obtained using multivariate analysis methods. Meteorology and hydrology, 2008, no. 12, pp. 33-47. In Rus.

15. Feoktistov V.M., Kharin V.N., Spector E.N. Studying precipitation chemistry by multivariate analysis based on data of rural stations in Russian Barents region. Water resources, 2014, vol. 41, no. 4, pp. 393-403. In Rus.

16. Volden T., Reimann C., Dagestad A. Precipitation Sampling Manual. Barents Ecogeochemisty, NGU Report 99-128, p. 9.

17. Überla K. Faktornyiy analiz [Factor analysis]. Moscow, Statistics Publ., 1980. $398 \mathrm{p}$.

18. Kim J.-O., Muller C.W., Klecka U.R., Oldenderfer M.S., Blashfield R.K. Faktorny, diskriminantny i klasterny analiz [Factor, discriminant and cluster analysis]. Moscow, Finance and statistics Publ., 1989. 215 p.

Information about the authors

Vladimir M. Feoktistov, Cand. Sc., associate professor, Petrozavodsk State University.

Marina M. Leri, Cand. Sc., research associate, Institute of Applied Mathematical Research of Karelian Research Centre of RAS.
19. Yakhnin E.Ya., Tomilina O.V., Chekushin V.A., Salminen R. Sravnitelny analiz dannykh o sostave atmosfernykh osadkov i snezhnogo pokrova na territorii Leningradskoy oblasti i yugovostochnoy Finlyandii i utochnenie parametrov vypadeniya tyazhelykh metallov [Comparative analysis of data on the composition of atmospheric precipitation and snow cover on the territory of the Leningrad region and South-Eastern Finland and to specify the parameters of the atmospheric deposition of heavy metals]. Ekologicheskaya khimia, 2003, vol. 12, no. 1, pp. 1-12.

20. Melchakov U.L. Zakonomernosti elementoperenosa v sisteme «pochva-atmosfera» (na primere Severnogo Urala) [Regularities of element transfer in system "soil-atmosphere» (the north Urals as an example)]. Litosfera, 2008, no. 2, pp. 133-138.

21. Yudovich Ya.E., Ketris M.P. Geokhimiya margantsa v protsessakh gipergeneza: obzor [Manganese geochemistry in supergene processes. A review]. Biosfera, 2013, vol. 5, no. 1, pp. 21-36.

22. Zavgorodnyaya R.E. Mikroelementny sostav nekotorykh torfyanykh pochv Karelii raznykh srokov osvoeniya [Microelement composition research of Karelian peat soils at different stages of utilization]. Uchenie zapiski Petrozavodskogo gosudarstvennogo universiteta, 2015, no. 8 (153), pp. 111-114.

23. Vinogradova A.A., Ivanova Yu.A. Antropogennaya nagruzka na ekosistemy Kostomukshskogo prirodnogo zapovednika: atmuksha natural reserve: atmospheric channel]. Moscow, Fizmatlit Publ., 2013. 82 p. mosferny kanal [Anthropogenic load on ecosystems of Kosto-

Received: 23 December 2020. 